\title{
Моделирование параметров бетавольтаического элемента на основе тритида титана
}

\author{
(C) А.А. Свинцов ${ }^{1}$, Е.Б. Якимов ${ }^{1,2}$, М.В. Дорохин ${ }^{3, \uparrow}$, П.Б. Демина ${ }^{3}$, Ю.М. Кузнецов ${ }^{3}$ \\ ${ }^{1}$ Институт проблем технологии микроэлектроники и особочистых материалов Российской академии наук, \\ 142432 Черноголовка, Россия \\ ${ }^{2}$ Национальный исследовательский технологический университет „МИСиС“, \\ 119049 Москва, Россия \\ ${ }^{3}$ Научно-исследовательский физико-технический институт \\ Нижегородского государственного университета им. Н.И. Лобачевского, \\ 603950 Нижний Новгород, Россия \\ ฯ E-mail: dorokhin@nifti.unn.ru
}

(Получена 10 апреля 2018 г. Принята к печати 17 апреля 2018 г.)

\begin{abstract}
Проведено моделирование $\beta$-вольтаических элементов питания, представляющих собой объединенные источник и преобразователь $\beta$-частиц. В качестве источника использовано соединение ТіТ 2 , содержащее радиоактивный изотоп трития. В качестве преобразователя рассмотрены структуры на основе полупроводниковых материалов, наиболее часто использующихся при разработке элементов питания на $\beta$-вольтаическом эффекте: $\mathrm{Si}, \mathrm{SiC}$, GaAs. C применением метода Монте-Карло рассчитаны основные параметры источников, в частности, выполнены оценки предельно достижимого значения тока короткого замыкания.
\end{abstract}

DOI: $10.21883 /$ FTP.2019.01.46995.8884

\section{1. Введение}

Бета-вольтаические элементы рассматриваются в качестве перспективных долгоживущих источников питания для маломощных микро- и наноэлектронных, а также микроэлектромеханических систем [1-5]. Они могут эффективно использоваться в системах, потребляющих мощности в диапазоне $10-10^{5} \mathrm{HBT}$, ограниченных по размерам (менее $1 \mathrm{~cm}^{3}$ ) и(или) работающих длительные периоды времени (25 лет и более). Бета-вольтаические батареи состоят из источника $\beta$-излучения и полупроводниковой структуры, преобразующей энергию $\beta$-излучения в электрический ток.

Среди радиоизотопов, использующихся в качестве источника в таких элементах, одним из наиболее распространенных является тритий вследствие его относительной дешевизны, коммерческой доступности и низкой энергии $\beta$-частиц, понижающей как вероятность радиационных повреждений структуры, так и радиационную опасность для потребителя. Тритий может использоваться в виде газа, однако для компактных $\beta$-вольтаических батарей более удобно его использование в составе твердых соединений, например тритида титана.

Для оптимизации $\beta$-вольтаических источников энергии и реалистичной оценки их предельных параметров необходимо разработать методы моделирования взаимодействия электронов, эмитированных из источника, с материалом преобразователя. Несмотря на важность этой проблемы, число работ, посвященных моделированию $\beta$-вольтаических источников на основе трития, сравнительно мало [6,7] и существенно меньше, чем для источников на основе Ni-63 ([8] и ссылки в этой работе). При этом даже в цитированных работах $[6,7]$ надежность полученных результатов вызывает сомнения вследствие целого ряда используемых предположений, в частности, в [7] спектр электронов заменялся их средней энергией и не учитывалось, что эмиссия электронов происходит изотропно по углам вылета, а в [6] энергетический спектр был разделен всего на 5 диапазонов и не учитывалось, что электроны эмитируются равномерно по глубине радиоактивной пленки тритида титана. Тем не менее расчеты, проведенные в [6], продемонстрировали важность учета реального спектра $\beta$-частиц и их изотропного распределения по углам вылета.

В [8] была предложена методика, позволяющая оценить параметры $\beta$-вольтаического элемента на основе радиоактивного источника с изотопом Ni-63 и реального полупроводникового преобразователя. В основе этой методики лежит моделирование методом Монте-Карло распределения скорости генерации неравновесных носителей заряда по глубине и измерение в растровом электронном микроскопе (РЭМ) параметров преобразователя, необходимых для расчетов вероятности собирания. Программа для моделирования методом Монте-Карло, разработанная в $[9,10]$, учитывала распределения $\beta$-частиц по углам вылета, толщине радиоактивной пленки и по энергиям, а также поглощение в пленке радиоизотопа $[10]$, что позволяет проводить более точные вычисления по сравнению с приближенными методами, использованными в [7,11-15].

В настоящей работе использованная в $[9,10]$ программа была адаптирована для источника на основе тритида титана. В результате была выполнена оценка предельных параметров $\beta$-вольтаических элементов на основе данного материала. 


\section{2. Моделирование потерь энергии $\beta$-частиц}

Для расчета зависимости скорости генерации неравновесных носителей заряда от глубины методом Монте-Карло вычислялись потери энергии электронов по глубине, а затем запасенная энергия делилась на среднюю энергию генерации электронно-дырочной пары (энергия ионизации). Расчеты были выполнены для полупроводниковых материалов, наиболее часто использующихся в качестве преобразователя $\beta$-вольтаической энергии: $\mathrm{Si}, \mathrm{SiC}, \mathrm{GaAs}$. Потери энергии $\beta$-частиц по глубине рассчитывались методом Монте-Карло с использованием программы, описанной в $[9,10]$. Для описания электрон-электронных столкновений использовалось приближение непрерывных потерь энергии, а для упругих столкновений электронов с ядрами применялось экранированное сечение рассеяния Резерфорда [16]. Алгоритм расчета был специально приспособлен для быстрого моделирования многослойных структур. Для моделирования $\beta$-распада в слое тритида титана траектории электронов начинались равномерно по толщине слоя и изотропно по направлению вылета электронов. При расчете использовался полный спектр $\beta$-частиц [17]. Предполагалось, что состав тритида титана $\mathrm{TiT}_{2}$, его плотность $3.8 \Gamma / \mathrm{cm}^{2}$, а удельная активность $4090 \mathrm{Kи} / \mathrm{cm}^{3}$. Предполагалось также, что пленка наносится непосредственно на полупроводниковый преобразователь, например, в качестве барьера Шоттки.

Рассчитанная зависимость поглощенной в $\mathrm{Si}$ энергии от толщины радиоактивной пленки приведена на рис. 1. Видно, что при толщине пленки $\sim 0.3-0.8$ мкм поглощенная энергия практически насыщается за счет эффекта самопоглощения в источнике, что хорошо коррелирует со значениями, полученными в [6]. Из данных, показанных на рис. 1, можно оценить значение поглощенной мощности в $\mathrm{Si}$, а также долю эмитированной источником полной энергии, которая поглощается в $\mathrm{Si}$.

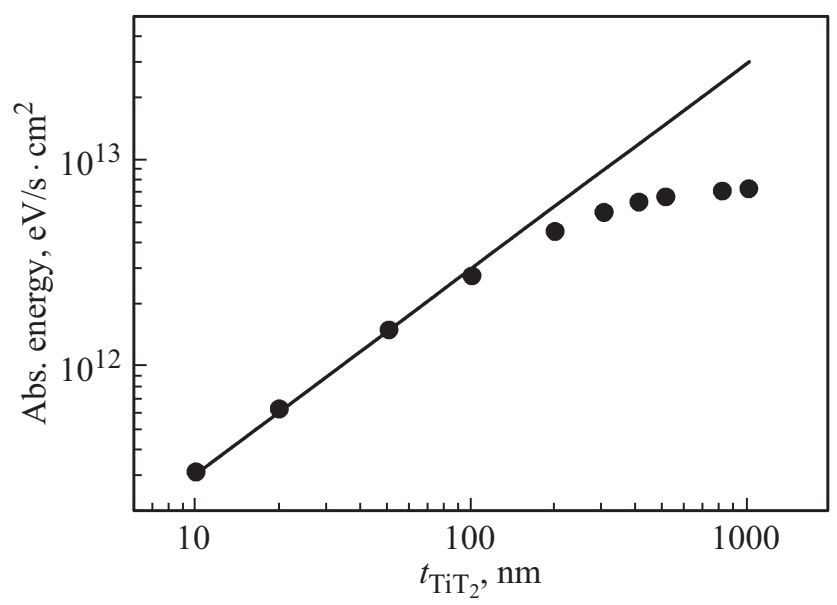

Рис. 1. Зависимость поглощенной в $\mathrm{Si}$ энергии $\beta$-излучения из пленки тритида титана от толщины пленки.

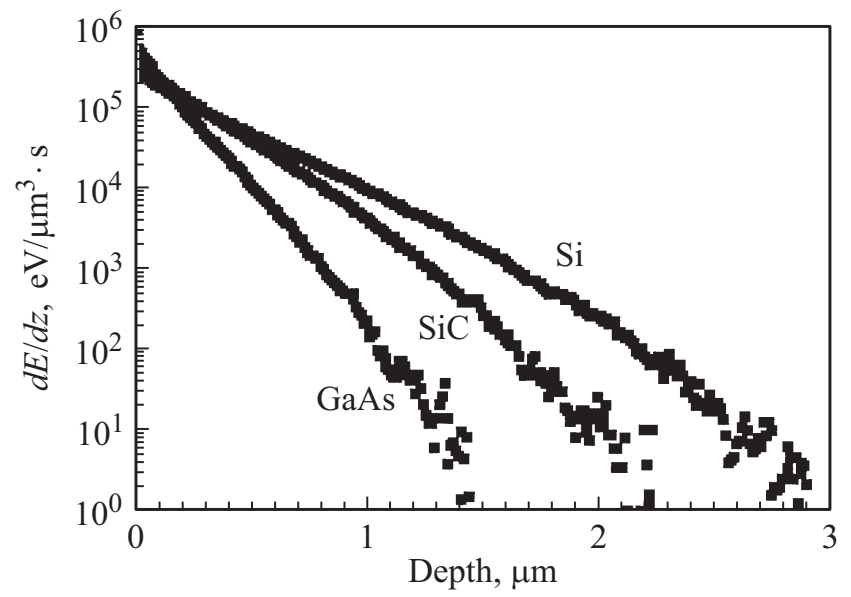

Рис. 2. Зависимости поглощенной энергии $\beta$-излучения от глубины, рассчитанные для $\mathrm{Si}, \mathrm{GaAs}$ и $\mathrm{SiC}$.

Для пленки толщиной 500 нм значение поглощенной энергии составило $6.7 \cdot 10^{12} э \mathrm{~B} / \mathrm{c} / \mathrm{cm}^{2}=419 \mathrm{HBT} / \mathrm{cm}^{2}$, что также хорошо коррелирует со значением, полученным в [6]. Доля эмитированной энергии, поглощенная в $\mathrm{Si}$, при такой толщине источника составила $2.7 \%$. Следует отметить, что эта доля, т.е. эффективность элемента при толщинах радиоактивной пленки меньше 100 нм, может достигать значений порядка $6 \%$, однако уменьшение толщины источника будет приводить к понижению мощности элемента.

На следующем этапе моделирования были рассчитаны зависимости поглощенной в преобразователе энергии от глубины поглощения $\beta$-частицы для $\mathrm{Si}, \mathrm{SiC}$ и $\mathrm{GaAs}$. В качестве примера на рис. 2 приведены зависимости, рассчитанные для радиоактивной пленки толщиной 1 мкм. Видно, что рассчитанные зависимости близки к экспоненциальным. В случае $\mathrm{Si}$ практически вся энергия $\beta$-излучения поглощается в слое толщиной 3 мкм. B случаe GaAs уже 1.5 мкм достаточно, чтобы поглотить практически всю энергию $\beta$-излучения. Далее, для определения скорости генерации неравновесных носителей заряда $g(z)$ поглощенную энергию следует разделить на среднюю энергию, необходимую для генерации электронно-дырочной пары. Для приведенных материалов она равна 3.63 эВ для $\mathrm{Si}[18,19], 4.35$ эВ для $\mathrm{GaAs}[18,19]$ и 8.6 эВ для $\mathrm{SiC}[20]$.

С учетом полученных значений поглощенной энергии были рассчитаны зависимости скорости генерации электронно-дырочных пар от глубины.

\section{3. Расчет тока короткого замыкания}

Ток короткого замыкания $I_{s c}$ рассчитывался как интеграл по глубине $z$ произведения скорости генерации неравновесных носителей заряда $g(z)$ на вероятность собирания $\psi(z)$. Такая процедура обычно используется 
для расчета тока, индуцированного электронным пучком [21-24].

$$
I_{s c}=e \int_{0}^{\infty} \psi(z) g(z) d z .
$$

Как показано в [21], вероятность собирания $\psi(z)$, которая представляет собой ток, индуцированный единичным зарядом на глубине $z$, может быть получена из решения однородного диффузионного уравнения:

$$
\partial^{2} \psi(z) / \partial z^{2}-\psi(z) / L^{2}=0,
$$

где $L=(D \tau)^{1 / 2}, D$ и $\tau-$ соответственно диффузионная длина, коэффициент диффузии и время жизни неравновесных носителей заряда. В случае барьера Шоттки граничные условия $\psi(W)=1$ и $\psi(z) \rightarrow 0$ при $z \rightarrow \infty$, где $W$ - ширина области пространственного заряда (ОПЗ), и $\psi(z)=1$ при $z<W$. Для любой полупроводниковой структуры $\psi(z)$ можно рассчитать на основе измерений зависимости индуцированного электронным пучком тока от энергии пучка $[23,25]$. В предположении, что вероятность собирания близка к 1, можно рассчитать предельные значения $I_{s c}$ для $\beta$-вольтаического элемента на основе тритида титана. Подобный расчет был выполнен для $\mathrm{Si}, \mathrm{GaAs}$ и $\mathrm{SiC}$, в результате были получены значения 322, 219 и $140 \mathrm{HA} / \mathrm{cm}^{2}$ соответственно. Указанные значения заметно ниже значений, рассчитанных для газообразного трития [26], особенно при повышенных давлениях, однако толщина тритида титана меньше 1 мкм, тогда как линейный размер камеры с тритием $\sim 1 \mathrm{cM}$.

Если сравнивать эти значения с рассчитанными для $\beta$-источника, содержащего 20\% изотопа Ni-63 [10], то для $\mathrm{Si}$ и $\mathrm{SiC}$ они в $\sim 2.5$ раза больше. Но при этом следует учитывать, что период полураспада Ni-63 около 100 лет, а увеличение его содержания в радиоактивной пленке может позволить достичь таких же значений $I_{s c}$.

Работа финансировалась в рамках государственного задания № 007-00220-18-00 в ИПТМ РАН, № 16.7443.2017/БЧ — в НИФТИ ННГУ.

\section{Список литературы}

[1] L.C. Olsen, P. Cabauy, B.J. Elkind. Physics Today, 65 (12), 35 (2012).

[2] Ю.С. Нагорнов. Современные аспекты применения бетавольтаического эффекта (Ульяновск, УлГПУ, 2012).

[3] M.A. Prelas, C.L. Weaver, M.L. Watermann, E.D. Lukosi, R.J. Schott, D.A. Wisniewski. Prog. Nucl. Energy, 23, 117 (2014).

[4] S.T. Revankar, T.E. Adams. J. Energy Power Sources, 1, 321 (2014).

[5] T.R. Alam, M.A. Pierson. J. Energy Power Sources, 3, 11 (2016).

[6] H. Li, Y. Liu, R. Hu, Y. Yang, G. Wang, Z. Zhong, S. Luo. Appl. Radiat. Isotopes, 70, 2559 (2012).
[7] C. Thomas, S. Portnoff, M.G. Spencer. Appl. Phys. Lett., 108, 013505 (2016).

[8] E.B. Yakimov. Appl. Radiat. Isotopes, 112, 98 (2016).

[9] В.Н. Павлов, В.Я. Панченко, М.А. Поликарпов, А.А. Свинцов, Е.Б. Якимов. Поверхность, 9, 46 (2013).

[10] С.И. Зайцев, В.Н. Павлов, В.Я. Панченко, М.А. Поликарпов, А.А. Свинцов, Е.Б. Якимов. Поверхность, 9, 9 (2014).

[11] H. San, S. Yao, X. Wang, Z. Cheng, X. Chen. Appl. Radiat. Isotopes, 80, 17 (2013).

[12] C.E. Munson IV, M. Arif, J. Streque, S. Belahsene, A. Martinez, A. Ramdane, Y. El Gmili, J.-P. Salvestrini, P.L. Voss, A. Ougazzaden. J. Appl. Phys., 118, 105101 (2015).

[13] Ю.С. Нагорнов, В.Н. Мурашев. ФТП, 50, 17 (2016).

[14] А.А. Горбацевич, А.Б. Данилин, В.И. Корнеев, Э.П. Магомедбеков, А.А. Молин. ЖТФ, 86 (7), 94 (2016).

[15] С.В. Булярский, А.В. Лакалин, И.Е. Абанин, В.В. Амеличев, В.В. Светухин. ФТП, 51 (1), 68 (2017).

[16] L. Reimer. Scanning Electron Microscopy, 45, 57 (1998).

[17] М. Борн. Атомная физика (М., Наука, 1965).

[18] T. Kobayashi. Appl. Phys. Lett., 21, 150 (1972).

[19] R.C. Alig, S. Bloom. Phys. Rev. Lett., 35, 1522 (1975).

[20] А.А. Лебедев, А.М. Иванов, Н.Б. Строкан. ФТП, 38, 129 (2004).

[21] C. Donolato. Appl. Phys. Lett., 46, 270 (1985).

[22] Е.Б. Якимов. Завод. лаб., 68, 63 (2002).

[23] E.B. Yakimov. J. Alloys Comp., 627, 344 (2015).

[24] E.B. Yakimov. Jpn. J. Appl. Phys., 55, 05 FH04 (2016).

[25] Е.Б. Якимов. Поверхность, 3, 65 (2004).

[26] B. Liu, K.P. Chen, N.P. Kherani, S. Zukotynski. Appl. Phys. Lett., 95, 233112 (2009).

Редактор Г.А. Оганесян

\section{Modeling of the titanium tritide-based beta-voltaic cell parameters}

\author{
A.A. Svintsov ${ }^{1}$, E.B. Yakimov ${ }^{\mathbf{1}, 2}$, M.V. Dorokhin ${ }^{3}$, \\ P.B. Demina ${ }^{3}$, Yu.M. Kuznetsov ${ }^{3}$ \\ ${ }^{1}$ Institute of Microelectronics Technology, \\ Russian Academy of Sciences, \\ 142432 Chernogolovka, Russia \\ ${ }^{2}$ National Research Technological University „MISiS“, \\ 119049 Moscow, Russia \\ ${ }^{3}$ Physical Technical Research Institute of \\ N.I. Lobachevsky State University of Nizhny Novgorod, \\ 603950 Nizhny Novgorod, Russia
}

\begin{abstract}
Modeling of $\beta$-voltaic power cells, which consist of combined beta-particles source and converter was carried out. A $\mathrm{TiT}_{2}$ compound containing a radioactive isotope of tritium was used as a source. As a converter we considered the structures based on semiconductor materials, which are most commonly used for the $\beta$-voltaic power cells developement: $\mathrm{Si}, \mathrm{SiC}$ and $\mathrm{GaAs}$. Using the Monte Carlo simulation method, the main parameters of the sources were calculated, in particular, the maximum achievable short-circuit current values were estimated.
\end{abstract}

